\title{
Schizophrenia and mental retardation in an adult male with a de novo interstitial deletion 9(q32q34.1)
}

\author{
Jonathan P Park, John B Moeschler, Susan Z Berg, Doris H Wurster-Hill
}

\begin{abstract}
A 28 year old man with mental retardation and therapeutically controlled schizophrenia was found to have a de novo interstitial deletion in the long arm of a chromosome 9 (46,XY,del(9)(q32q34.1). Additional phenotypic abnormalities included short stature, a short webbed neck with a low posterior hairline, dysmorphic facies, a narrow palate with an inverted $\mathbf{V}$ soft palate, and tapered fingers with bilateral short fifth metacarpals. Interstitial deletion of chromosome 9 is a rare finding and we are aware of only one other case involving the q32q34.1 region.
\end{abstract}

Few cases of interstitial deletion of the long arm of chromosome 9 have been reported. We know of two cases involving deletion of a portion of the secondary constriction and adjacent euchromatin. ${ }^{12}$ Ying et al reported a more distal deletion (q22q32) in an infant boy with craniofacial abnormalities including hypotelorism, narrow palpebral fissures, sclerocornea, and supraorbital ridge hypoplasia, in addition to other abnormalities including preaxial polydactyly and syndactyly of the toes, hirsutism, unilateral renal dysplasia, and accessory spleens. Turleau et al assigned breakpoints similar to those in our case (q32q34) in their study of a 10 month old male with

Department of Pathology, Dartmouth-Hitchcock Medical Center, Hanover, New Hampshire 03756, USA.

J P Park, D H Wurstler-Hill

Department of Biological Sciences, Dartmouth College, Hanover, New Hampshire, USA.

J P Park

Clinical Genetics and Child Development Center, Dartmouth-Hitchcock Medical Center, Hanover, New Hampshire, USA.

J B Moeschler, S Z Berg

New Hampshire Department of Public Health, Concord, New Hampshire, USA.

S Z Berg

Correspondence to Dr Park.

Received for publication 2 August 1990.

Revised version accepted for publication 4 October 1990. brachycephaly, hypoplastic midface, frontal bossing, deep nasal bridge, short nose, apparently low set, dysmorphic ears, and downward slanting palpebral fissures.

\section{Case report}

The proband is a 28 year old man who was first referred for genetic evaluation at the age of 2 years 3 months for mental retardation, ptosis of the right eye, and apparently small genitalia. At 4 years 8 months a mental age of 3.7 years and an IQ of 75 were recorded. At 15 years of age the proband was again referred with indications of dysmorphic features, slow speech development, and delayed growth. A chromosome study showed a normal modal number of 46 and the five cells karyotyped were interpreted as normal.

At 28 years of age the proband's height is $1.57 \mathrm{~m}$, weight $80.7 \mathrm{~kg}$, and head circumference $55.5 \mathrm{~cm}$ (50th centile). The phenotype (fig 1) includes a short neck with slight webbing and a low posterior hairline, altered ear morphology, hypoplastic midface, small mouth with downturned corners, short philtrum,

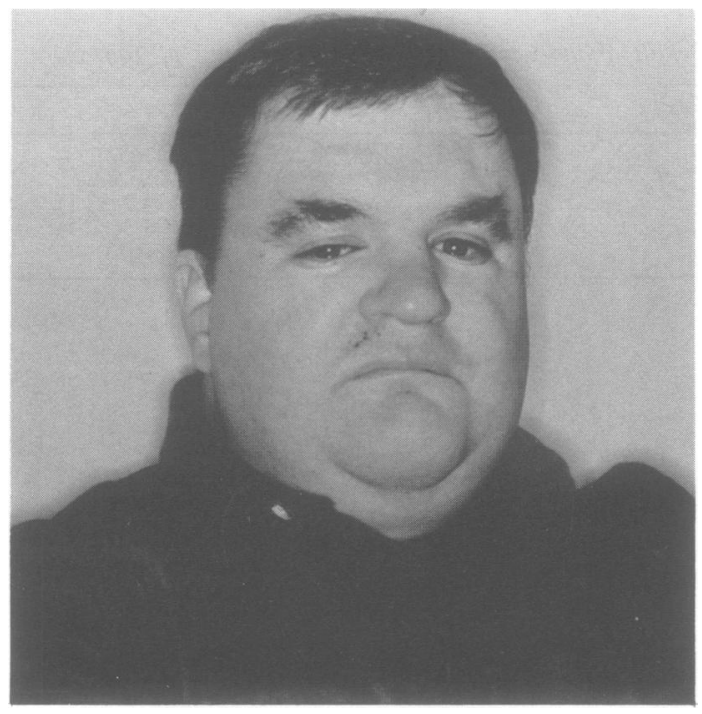

Figure 1 The proband aged 28 years. 


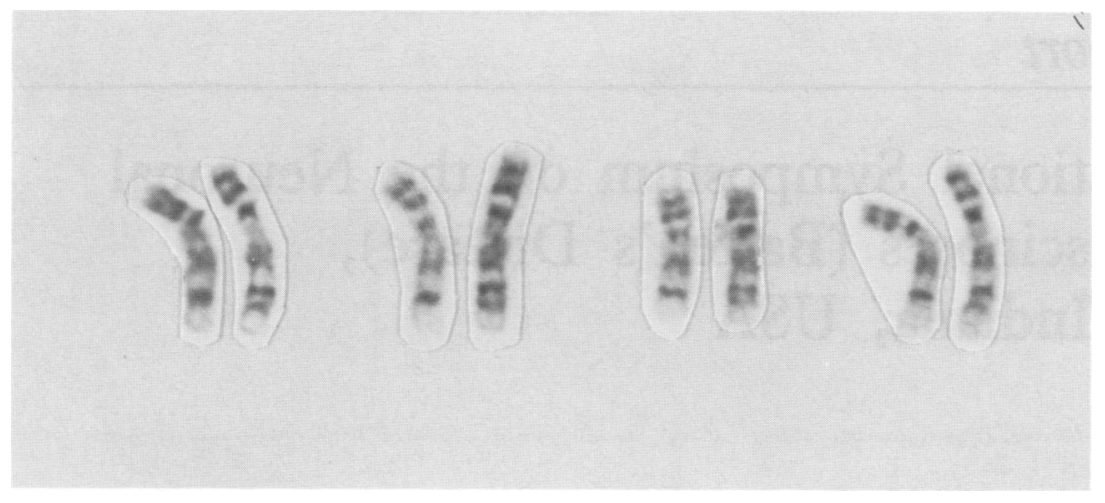

Figure 2 Partial G banded karyotypes showing the deleted chromosome 9 on the lefi of each pair and the normal homologue on the right.

narrow palate with an inverted $\mathrm{V}$ soft palate, and tapered fingers with bilateral short fifth metacarpals. The proband began hearing and talking to imaginary voices at the age of 23 years. He has been diagnosed as having paranoid schizophrenia characterised by auditory hallucinations, agitation, labile affect, thought confusion, and delusional beliefs, and is currently treated with trifluoperazine (Stelazine ${ }^{\circledR}$ ) for this condition.

Repeat cytogenetic study of skin fibroblasts $(60$ cells) and peripheral lymphocytes ( 20 cells) showed an interstitial deletion in the long arm of chromosome 9 (q32q34.1) in all cells analysed (fig 2). The parents' chromosomes are normal. The parental origin of the deleted chromosome 9 could not be determined cytogenetically owing to the lack of constitutive heterochromatic heteromorphisms in the proband. Upon re-examination of the proband's original study, a mixture of normal and abnormal cells emerged. Of a total of 31 cells, 11 were scored positive for the deletion, while 20 were scored as normal.

\section{Discussion}

A study of the known landmarks coinciding with the breakpoints in our case show two fragile sites at 9q32 (a folic acid rare site and an aphidicolin type common site) and the ABO blood group locus at $9 \mathrm{q} 34.1-\mathrm{q} 34.2 .^{4}$ The previously reported case of $\operatorname{del}(9)$ (q32q34) 1 shares some non-specific anomalies with those in our case; however, long term follow up is lacking and specific comparisons between our adult proband and the infant reported by Turleau $e t a^{1}$ are difficult. It is of interest, in our case, that a proportion of normal cells was observed in the initial analysis of peripheral lymphocytes and that this population of cells was not seen in subsequent (13 years later) extensive analysis of skin fibroblasts or periphera lymphocytes. Of the rarely reported interstitial deletions of chromosome 9 , our case is the only one to be associated with schizophrenia.

1 Turleau C, de Grouchy J, Chabrolle JP. Délétions intercalaires de q. Ann Genet (Paris) 1978;21:234-6.

2 Wisniewski L, Purdy G, Hassold T, et al. An interstitial deletion f chromosome 9 in a girl with multiple congenital anomalies. f Med Genet 1977;14:455-9.

3 Ying KL, Curry CIR, Rajani KB, Kassel SH, Sparkes RS. De novo interstitial deletion in the long arm of chromosome 9: new chromosome syndrome. 7 Med Genet 1982;19:68-70.

4 Human Gene Mapping 10. Tenth international workshop on human gene mapping. Cytogenet Cell Genet 1989;51:209-12. 